\title{
RE-ACTIVATE THE INTERNAL AREAS: CLASSIFICATION, RESTORATION, PARTICIPATION PLANNING AND GUIDELINES AS TOOLS FOR THE REGENERATION OF THE VERNACULAR HERITAGE
}

\author{
B. Scala $1, *$ \\ ${ }^{1}$ Università degli Studi di Brescia, via Branze 53, 25100, Brescia, Italy - barbara.scala@unibs.it
}

Commission II - WG II/8

KEY WORDS: Vernacular heritage, Conservation, Resilience, Valorisation, Rural architecture

\begin{abstract}
:
The report aims to present the experience of a project called "Resilient Valleys", which covers the area of the high valleys Trompia and Sabbia, near Brescia, Italy. This is a peripheral territory, which is suffering depopulation and losing the ability to attract people and resources, both economic and environmental. With this project, we have tried to overcome the crisis linked to the impoverishment and fragmentation of the social fabric, by activating virtuous processes of development and participation. The "Resilient Valleys" project, carried out as part of the Cariplo Foundation's "AttivAree" programme, aimed to give new life to the territories by enhancing their cultural, historical and environmental potential. One of the paths had the purpose to produce a change in the way we approach restoration, enhancement and conservation of the building heritage, of which this area is rich. This activity has been carried out through successive phases: first, mapping of architectural resources considered as identity heritage; second, new courses for people actively involved in the building field; third, printing "Guidelines for intervention" for vernacular buildings. A further activity concerned the reactivation of a rural complex in the territory of Rebecco (Italy). The project consisted in the architectural restoration of three abandoned and partially collapsed buildings. While testing the indications of the Guidelines mentioned above, the rural complex has also been revised from an agricultural-ecological-cultural point of view. The project is characterized by a strong cross over between identity culture and social cohesion of the territory.
\end{abstract}

\section{THE “ATTIV-AREE” PROGRAMME}

\subsection{Introduction}

In 2016 the Cariplo Foundation, (Banking Foundation) opened a new call for proposals with the aim of financing projects that would act in fragile territorial areas which present situations of abandonment and discomfort for the few remaining residents (1). The interest of the call is in the choice to involve numerous economic and cultural fields and aspects that have potential interests in the territories (Della Torre, 2015). The projects that participated in the call for proposals were required to show an indepth knowledge of environmental, social, cultural, economic and research aspects. The idea behind the programme is to give space to innovative lines of action in order to offer "positive and lasting responses to the problems of isolation and abandonment, transforming them into opportunities for innovation, growth and identity recognition".

The "Resilient Valleys" project, led by the Mountain Community of Valle Trompia and Valle Sabbia, is one of the winning projects and involves an area covering 600.44 square kilometres and 25 mountain municipalities. The project proposed the construction of a resilient territory through activities and actions that focus on weak sectors, looking for support in more fertile areas such as: technological innovation, services to support the community, business activities (especially proposed by young people), culture, tourist accommodation based on solidarity and sustainable use of the territory.

Along with this great commitment, the Mountain Communities and the Cariplo Foundation have considered appropriate to give space to the recovery of the traditional building heritage. The aim is to create and strengthen in a more solid and physically perceptible way the feeling of belonging to the territory. The University of Brescia was commissioned to give concrete shape to the project: the aim was to identify and study the historical heritage and identity. Formally, the action at the base of this path has its own title: "Mapping and enhancement of the identity building heritage in the two valleys" (Lamair, 1997). The key points of the activity carried out were: 1 ) improve the conservation and enhancement of identity resources; 2) support the recovery of a landscape able to increase the attractiveness of the places; 3 ) guarantee and at the same time ensure the maintenance of a cultural heritage seriously exposed to processes of abandonment and degradation.

\footnotetext{
* Corresponding author

1 The principles of the Active Areas Programme and the motivations that push people to take an interest in internal areas are explained by Elena Jachia, Director of the Cariplo Foundation Environmental Area: '.. they are territories rich in cultural, natural, social resources, human capital, ideas and experiences whose productivity in the years after the First World War has been subordinated to urban centres. They have undergone a progressive abandonment due to the imposition of alternative cultural models... due to an increasing difficulty of access to services. Intervening in support of the internal areas means raising ... turning the spotlight
}

on what is happening in these areas. It means focusing on sustainable local development as an engine of revitalization for the whole country... the more 'marginal' areas become a place of innovative experimentation'... 'Moreover, we have noticed an interesting convergence between national policies and individual and spontaneous phenomena of return to rural areas and agriculture and we thought we could give a contribution of ideas that would leverage the experience acquired in the field by the Cariplo Foundation, through some projects particularly significant for the territory'. 
The particularities of each valley have suggested two architectural typologies: the mountain huts for the Trompia Valley (Veronesi 2014) and the hydraulic factories for the Sabbia Valley (Marchesi, 2003) in Lombardia (Italy).

\subsection{Knowledge of the rural mountain heritage of the Trompia Valley and the hydraulic factories of the Sabbia Valley}

The analysis of the built heritage of the two valleys has been carried out during three years of work, giving a lot of space to the direct knowledge of the artefacts. In fact, we have verified how frequently this kind of situation arises: “... as the data archive grows, the heritage of the objects decreases. [...] There is a singular paradox for which, while the archive represents a growing form of capital a sort of fixed patrimony that is, so to speak, increased and capitalized through the contributions that are gradually added $-[. .$. the architectural assets that are the object of such attention degrade over time and fatally alter and change $[\ldots] ;[. .$.$] they therefore$ represent a decreasing patrimony that tends to disappear over time, almost as if these material resources would finally be elevated to the previous category, the archive of memories" (Dezzi Bardeschi, 1991). We have encountered this risk especially regarding productive buildings. In fact, numerous historians of the Valle Sabbia have dedicated themselves over the years to collecting archival material regarding the work carried out inside the factories. There is rarely evidence of buildings recovered for testimonial or didactic purposes in order to inform about the activity carried out inside them. No building or ruin found has been the object of an enhancement with the aim of illustrating the construction techniques and characteristics that have allowed its construction and conservation ${ }^{2}$.

\section{THE 'ATTIV-AREE' PROGRAM}

\subsection{The rural architectural heritage of the Valle Trompia}

In the case of the Trompia Valley, the historical knowledge and awareness of the consistency of rural artefacts proved to be quite modest. The rural building heritage was not known except for historical listings and photographs with a predominantly nostalgic character (Agostini, 2007). The volume of the farm was known through the number of animals that could be hosted inside. In fact, the rural buildings located at high altitudes are still in use for grazing and transhumance.

In order to identify the architectural features of the rural buildings located in the Valle Trompia area, inspections of the buildings have been organized - starting from the lists presented in the bibliography - focusing on those buildings where a greater "authenticity" and "integrity" was recognizable. In this regard, attention should be paid to the terms "authenticity" and "integrity". The UNESCO guidelines for the sites included in the World Heritage List define as "authentic" the architectures in which one recognizes characters and aspects that are expression of a local culture, even when they do not reflect the first construction of the building. "Integrity" is defined as the result of a transformation process despite which, over time, the significant characteristics of the architecture have been maintained without altering the intrinsic and extrinsic logic that generated them.

\footnotetext{
2 Valle Trompia's huts and farmhouses, so as Valle Sabbia's ovens and forges are part of the imaginary linked to many marginal areas, made of slowness, contemplation and taking time for oneself, made of places where one can fully experience the relationship with the natural elements and history, which can be interesting for the tourist. If the writing of guidelines for technicians and professionals, which ensure only the formal quality control of the
}

These definitions had the positive effect of increasing the number of architectures that have been visited and, consequently, of confirming their physical existence. Authenticity has therefore also been recognised to buildings in which modifications have been made. Transformations, repairs and adjustments, originated from empirical intuitions handed down from generation to generation, however expression of local culture, have allowed to keep alive rural buildings (Aliverti et al., 2006). These buildings are "containers of experience", which preserve a heritage of operational practices and knowledge that well represent the authenticity of everyday life. The multi-layered rural architecture, transformed over time, has been recognised as having a great wealth of meanings (Treccani, 1996). Restoration, repair and constant maintenance encourage better conservation situations (Bellini, 1996). Abandonment encourages deliberate tampering or rapid decay. The rural architectures that can be found along the mountains of the Valley and the nuclei of ancient formation are farmsteads and huts used for housing, production, agricultural work and breeding (houses, barns, stables, pigsties, cisterns, woodsheds, etc.).

Naturally, we rarely identify a unitary original architectural conformation, but rather a wealth of building characteristics. These express the commitment and effort that the alpine farmers that lived in these buildings endured in their lives.

Through direct observation, we have noticed that one of the aspects that has influenced the change in the building types identified is the altimetric dislocation, which has facilitated or prevented the supply of building materials.

The farmsteads inside the inhabited nuclei (Figure 1) were usually built on several floors and arranged side by side, almost as to form a unitary and supportive body. On the ground floor, located on the road, there are porticoes with arches that identify and protect the entrance. On the front part of the upper levels there is a long and narrow balcony that connects the internal rooms.

Sometimes, an overhanging volume was built with wooden planks in order to create additional space. Inside this space was usually stored the hay, which had the additional purpose of protecting the outside of the house. The stone typically used, called Carniola di Bovegno (locally called 'tof'), is characterized by great lightness and workability and it is used to make arches, vaults, the columns of the porticoes and the corners of the walls.

The second typology of building identified (Figures 2 and 3) is an isolated farmhouse on two floors and facing the valley in order to gain exposure to the sun. On the ground floor is usually located the basement stable, with a very low ceiling made of wood.

The stable was rarely covered by a barrel vault. The size was proportionate to the number of animals housed and to the needs and possibilities of the family. Also, on the ground floor there was a room called 'casera' for the processing of milk and the storage of the products of the processing. A cellar to store the food, a barn and a side loggia to leave the harvest to mature completed the building. Near the construction there were other service areas: the woodshed, the pigsty, various shelters for farmyard animals and a well or a cistern for collecting water.

interventions, would have been the only outcome of action, the aim of true heritage conservation would not have been reached. However, these artefacts are today of little interest for new investments and it is not likely that they can be, in themselves, a lever for the local economy. Therefore, the desire for a deeper knowledge of them should not only be read through the lens of tourist attraction or real estate investment (topics often evoked). 


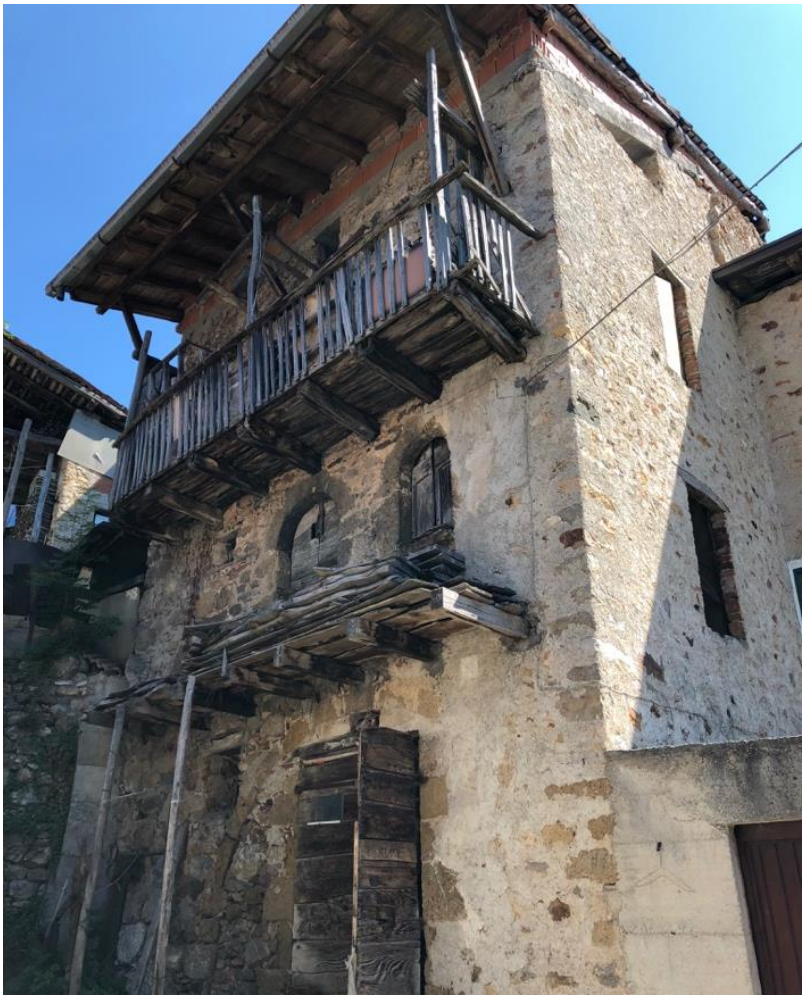

Figure 1. Farmhouse in Magno di Bovegno, Brescia (Italy)

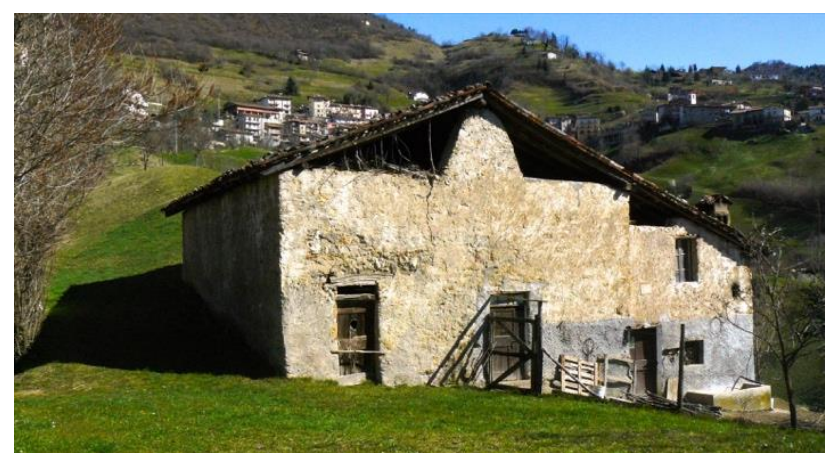

Figure 2. Farmhouse Marmentino, Brescia (Italy)

On the ground floor there was also a room with a fireplace used as dining room and to host the shepherds, while upstairs there was a room for sleeping, often only one big room for everyone. The masonry is in hewn stone with lime mortar joints (usually found in local limestone quarry), which sometimes cover the surface of the stone with a smoothing effect. Near the river 'Mella' that runs through the valley, the masonry structure is basically made of megalithic rocks (used for the foundations) and smaller pebbles collected directly from the river.

The external façade is characterized by small windows, which allow the light into the rooms, and trapezoidal openings near the eave line, which were used to ventilate the attic where the hay was stored.

The ceiling and roof structure have a main and secondary beam levels generally made of wood, above which are laid axes and rafters made from branches and trees of modest size. The pitch of the roof, covered in terracotta, shows consistent inclinations that sometimes reach the ground level. The eaves are usually made of wood and have a limited span/diameter, in order to facilitate the entry of light in the interior spaces.

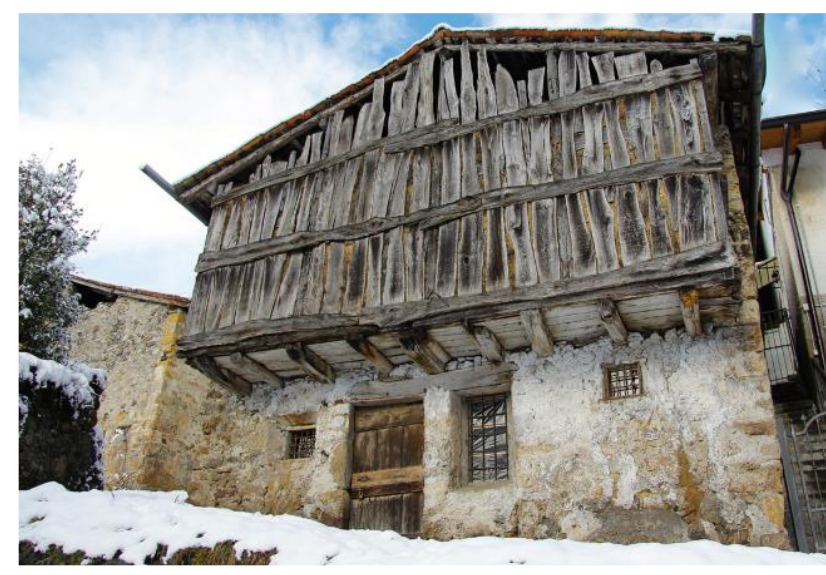

Figure 3. Barn in Ludizzo, Bovegno Brescia (Italy)

In buildings located at lower altitudes, windows and doors are usually made of wooden lintels with wooden sashes, while at higher altitudes they may also have stone lintels.

Frequently some vertical planks, obtained by cutting though tree barks and known as "skins" or "peels", are used as curtain walls on the façade to allow natural ventilation inside the barns.

The non-structural walls that divide the interior spaces are made of lightweight material and a wood beam composed of mediumsized joists, arranged vertically and horizontally to create a square or rectangular mesh. Between one beam and the other, various types of material are arranged, such as mortar mixed with straw or other vegetable fibres, laths and reeds.

Along the slopes of the upper valley we can observe the presence of alpine huts (Figures 4 and 5), located at different altitudes according to the routes and times of transhumance.

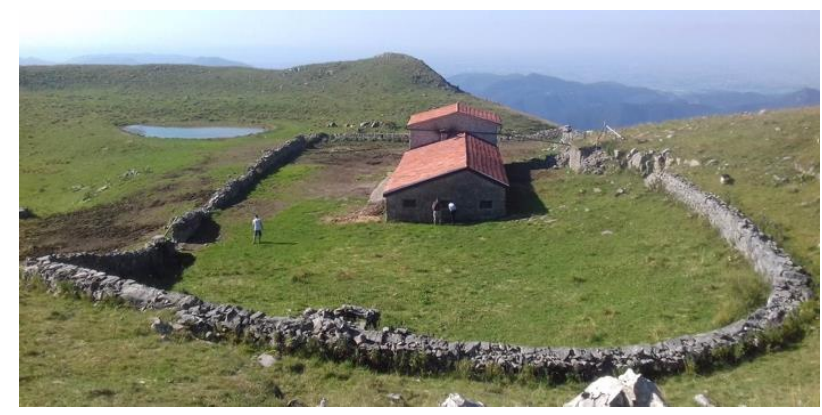

Figure 4. Farmhouse called 'Malga Due Signore' in Tavernole sul Mella, Brescia (Italy)

For this reason, they are divided into 'malga del piano', 'malga del maggengo' and 'malga dell'alpeggio'. Unlike the farmsteads described above, this type of rural property is still used with its original function.

The alpine huts, projected for seasonal use, are built with simple construction techniques and materials found on site. Their volume follows the morphology of the terrain and is oriented in relation to the meteorological situation of the place.

The organization of the building is spartan: a stable, a cheese processing room with storage, a room (usually without toilets). The structure is not equipped with heating, since it is used exclusively during the summer, and the only fireplace present is the one employed for milk cooking. 
The huts are made of stone and plastered with lime mortar; they have lintels, floors and roofs in wood and a roof made of tiles. The openings of the rooms are usually small because they need to prevent the sun from entering and making therefore the milk processing rooms too hot, but at the same time their presence ensures ventilation and cooling of the spaces.

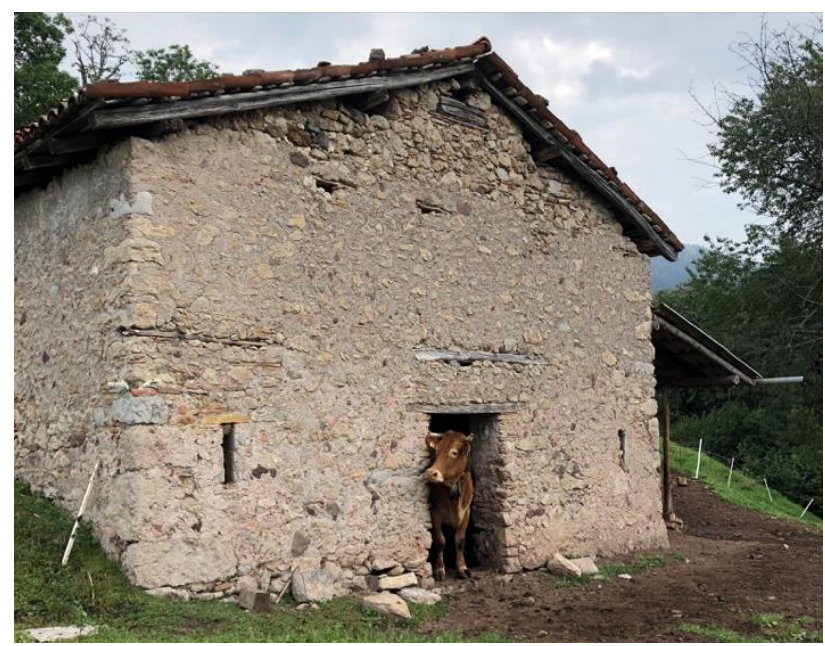

Figure 5. Farmhouse in Bumaghe, Bovegno, Brescia (Italy)

\subsection{The knowledge of building techniques}

Reading through the construction practices and conservation projects one can see how much commitment and dedication were there in the realization of historical buildings, which are the expression of an ancient wisdom handed down from generation to generation. For centuries, with very few variations in the activity, building sites have been a training ground for young people who began their profession in the field of architecture, alongside master's bricklayers, carpenters, house painter, etc.

The "practice" understood as a series of "effective gestures that have activated resources related to the context in which these practices took place" is different from the "technique" intended as a "specific procedure followed in the execution of a work, especially when it involves a manual activity or the use of instruments". Therefore, the practice takes into account the reality of situations and it is an expression of experience (Musso et al., 2008).

The results are often unique and heterogeneous, even if they can be traced back to common building guidelines (but not necessarily coinciding with them).

These definitions acquire meaning and value in reference to historical architecture, especially of rural character, generally unknown to specialized literature. In fact, the construction characteristics of rural mountain architecture are not systematic and the bibliographic repertoire of reference is usually represented by publications of a local or regional nature.

From these texts emerge mainly the different awareness of the authors who, even with very heterogeneous trainings (urban planners, geographers, historians, architects, etc.), have devoted themselves to the topic mainly because they were fascinated by it. On the contrary, studies in the field of the history of architecture have deepened the theme of anonymous constructions since the Twenties, when the interest in traditional forms of building saw concrete in-depth studies, and research on rural settlements took on a more systematic form. In the aftermath of the Second World War, the lively debate about rural dwellings was reopened and finally led to the adoption of the "Convention on Cultural Heritage" and the establishment of the "World Heritage List" in 1972.

Despite this, in recent decades there has not been a similar commitment in Italy and the activity on traditional architecture has not been regulated by specific legislation. The regulatory framework is generally binding and the interventions, even when they comply with urban planning rules (maintaining heights, volumes and surfaces), are often insufficient in terms of the quality of the materials and techniques employed (De Vita, 2009).

For centuries, the good building rules have been transferred to the building sites, which act as a guarantee of the historical and constructive values permanence, thanks to pre-modern repair practices. Today, new materials and new technologies have replaced the ancient knowledge and caused the dispersion of decisive information that could build up a tendency for the repair and reuse.

In addition, attention has rarely been given to finding ways and means to raise awareness of communities, administrations and decision-making bodies. Very often, also specific researches carried out at university level are not considered supportive to promote heritage protection policies.

\subsection{Tools for knowledge, protection and conservation}

As anticipated, the first step of the research concerned the reading of all the documents regarding rural buildings that were available in any field.

The bibliographic sources mainly concerned local history - often drafted for different purposes and by authors coming from heterogeneous backgrounds (geographers, historians, etc.). In these texts the buildings were either only the subject of photographs, often a little nostalgic, or described because they were recognized as significant by the local community or place where the breeding tradition is still active.

Internet sites related to the history of the valleys or individual municipalities participating in the project were also consulted. A useful reference for the location of rural buildings is the cartography contained in the urban plans at local and supralocal levels, in which are shown the buildings that have a culturalhistorical value to protect. The Provincial Territorial Coordination Plan of Brescia in force, approved in 2014, identifies the rural buildings as "areas, systems and elements of the landscape" (table 2.2), divided into rural architecture (for the territories of the plain) and mountain architecture (for the territories of the valleys), and defines guidelines for their protection in Annex I, "Regulations for the protection and enhancement of areas, systems and elements of the landscape of the province of Brescia" (Figure 6).

Finally, the censuses concerning the number of animals of the different breeders were consulted. Incredibly, it was easy to follow the movement of a sheep or a cow and find out the place where it was reared or moved during the summer.

The survey campaign was organized with the contribution of the Ecological Guards, who live in the area on a daily basis and helped to identify the correspondence between places and place names. The inspections were carried out starting from the highest altitudes (Figure 7), and then descending along the slopes of the mountains to enter the historical centres. 
To establish a better relationship with the territory, an interesting source of information consists of interviews with local history experts, who often have rich iconographic and photographic testimonies, and of life stories told by elderly people who, despite the fatigue, never abandoned the mountain realities of the valley

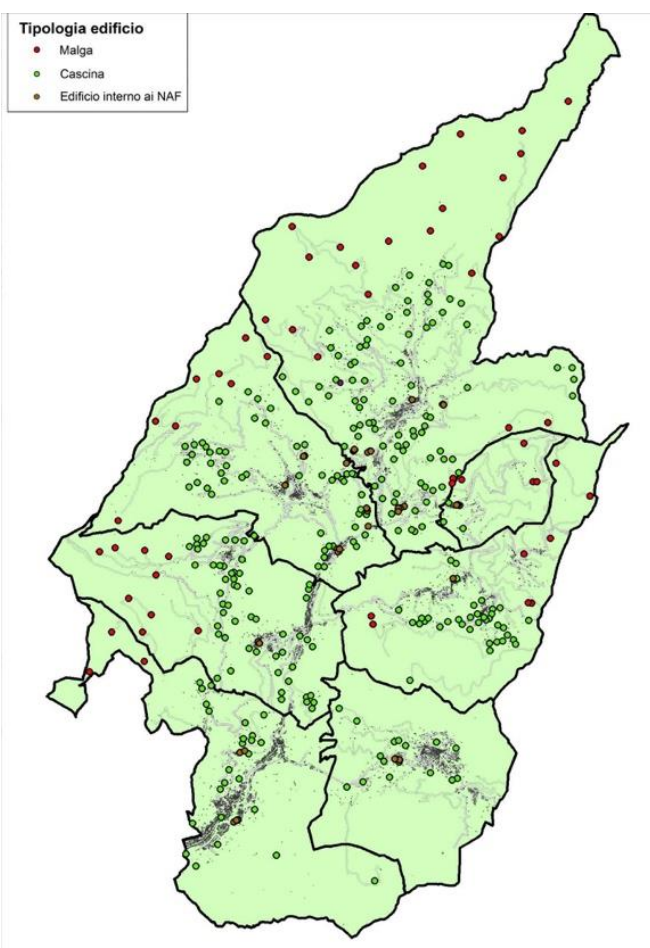

Figure 6. Map of rural buildings in the Trompia Valley divided by category.

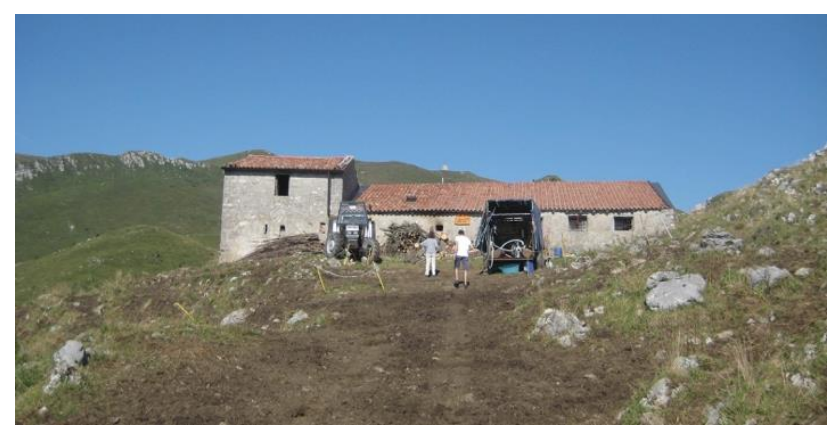

Figure 7. Farmhouse called 'Stalletti alti' in Tavernole sul Mella, Brescia (Italy).

A specific in-depth study, based on the map documentation found in the historical cadastres/registers kept in the State Archives of Brescia and Milan and available online, was aimed at assessing the time of construction and at identifying any changes in the rural heritage under study.

\subsection{The guidelines for the knowledge and conservation of the rural mountain architectural heritage of the Trompia Valley}

After the research phase, part of the work was devoted to the definition of guidelines for the knowledge and conservation of the architectural heritage in question. The guidelines provide recommendations, based on scientific literature and expert opinion, which are aimed at supporting the identification of the most appropriate operating methods in presence of particular conditions.
The guidelines are not practical rules to be applied in the exercise of an intellectual or manual activity, but they are a logical procedure through which we want to offer theoretical-methodological indications for a concretely feasible path, summarizing the various instances and verifying the correspondence of each choice with the premises (Scala, Boniotti, 2020).

The intent is to provide institutional subjects with support in making decisions during the phases of evaluation and planning of activities in the field of rural architecture, where it is necessary to have adequate knowledge of all types of building present; (for example, in case an institution wants to allocate public resources to the recovery of the heritage according to the financial means of the administration) (Moioli, Baldioli, 2018).

Moreover, this tool can be thought of as a complement to the existing database containing the list of obligations required in the presentation of the projects. These data are necessary to obtain the authorization from the landscape commissions of individual municipalities, or of the landscape commission of the Mountain Community of Valle Trompia (Figures 8 and 9).

The diffusion of the guidelines contents also acts as a stimulus for the owner and for the technicians working in the area to undertake activities on existing buildings that respect local characteristics, applying good conservation practices and ensuring the long-term care of the cultural heritage, without however inhibiting the freedom of the design, but rather stimulating the creativity of the designer.
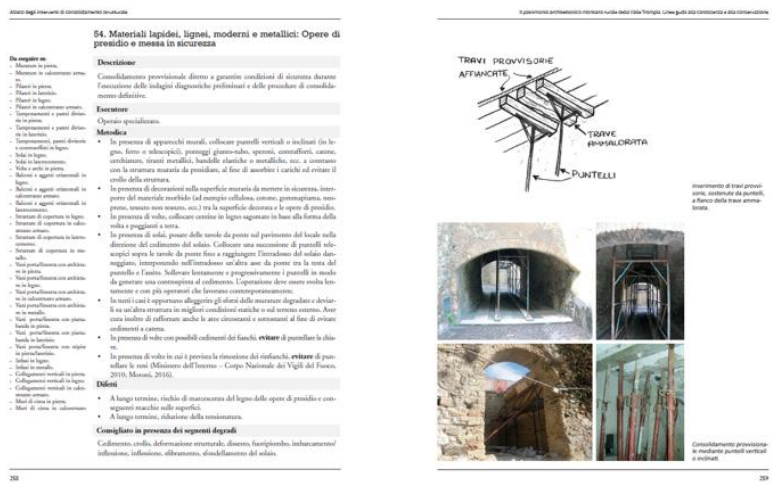

Figure 8. Example of an intervention data sheet.
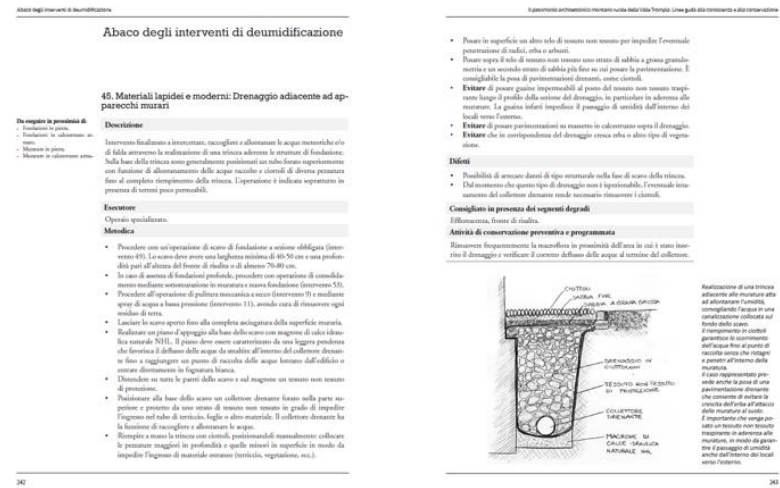

Figure 9. Example of an intervention data sheet.

In order to respond to the pragmatic, but not predictable, need of the readers who are not necessarily specialised, probably lacking adequate and up-to-date references on conservation, priority has been given to suggestions, regulatory guidelines, indications of 
good practices, first level technical advice of a general nature and closely connected with the territory in question. Only a few specialised operational procedures have been examined in-depth and described in a specific and detailed manner, in order to offer a method of building activities compatible with the building in question. We have specified which operators should be involved and their level of specialisation, the succession of the executive operation phases, the materials and technical solutions, the possible flaws that can be found in the work, the pathologies to which they refer, the preventive and programmed conservation procedures (Pracchi, 2008).

\subsection{A practical example: 'Rebecco farm'}

The inspections carried out on the mountains of the Trompia Valley in order to identify the characteristics and construction techniques preserved in the huts and farmsteads were followed by a phase of methodological research and experimental activity.

The aim was to test a programmatic and operational approach to be shared with technicians and professionals called to design projects for these artefacts, the public administrations that have a role in the control of the building activity, the students of the building schools that are being trained in order to be initiated into professions in the building field, the owners that have to decide how to intervene to recover a building heritage that can still be used today, but that at the same time has a great importance as an element that shapes the image of the local landscape.

The object of this experimentation is the built-up area located in Rebecco (Lavone di Pezzaze - Brescia-Italy) ${ }^{3}$. The focus of the 'Rebecco Farm' project - part of the "Resilient Valleys" programme - was to reactivate the rural complex in terms of agricultural-ecological-cultural support through a series of actions carried out by both the Active-Areas project and, more generally, the Mountain Community of Valle Trompia in the agri-food, cultural sector, with particular attention to educational services.

Given its strategic position, the 'Rebecco Farm' will be structured as a reception and interpretation centre of the territory, which will refer to all the spots activated in the internal area and already present in the museum and eco-museum offer (Francini, et al. 2017).

From an architectural point of view, the project consists in the recovery of two buildings now in a state of abandonment and partially collapsed, with a covered area of about 300 square meters, that became of public use through to a 20-year agreement. The two buildings in which the intervention is taking place are the expression/result of a previous conversion of use, following the crisis that affected the Valtrumplino territory in the first half of the XIX Century, when the transformation of iron ore - of which the valley is very rich - was subject to innovations that were not acquired in all the peripheral centres of the valley. Rebecco was born on the sixteenth floor of an old smelting furnace, of which charcoal kilns and underground rooms for the storage of 'loppe' (iron ore processing products) are still preserved in the basement (Simoni, 2010).

The charcoal kilns, despite being largely lost, are the largest body: today three rooms are preserved, two of which have no roof

\footnotetext{
www.youtube.com/watch?v=UrMboysDB6c;

www.youtube.com/watch?v=HxkfWfINC_o

4 The management (of the $\mathrm{B} \& \mathrm{~B}$ ) is entrusted to a group of cooperatives-companies operating in agriculture, training and culture. They have been selected through a participatory design
}

and the third, larger in width, was reused as a stable on the ground floor and as barn on the first floor. Of the other charcoal bunkers identified in the cadastral map of 1898, no traces of walls have been found, even during excavations.

In the reconversion from industrial to agricultural architecture, the planimetric survey, the masonry and the trend of the with its consistent inclination had been preserved. On the internal perimeter masonry, we can observe the holes of partially lost beams, while upstairs large plugged openings are visible, probably used to unload coal from above but not useful, with that width, to bring hay inside the room.

The masonry consists of large stones, picked up from the near Mella river which at this point presents a bend in its bed, put in place with lime mortar and punctually retiled with cement mortar. In the higher masonry the stones are replaced by smaller pebbles. The internal pavement, when present, is also in pebbles.

The second structure shows more renewed construction features, although its presence is already shown in the Napoleonic cadastre of 1805 . Only in the basement room do the walls show boulders of important dimensions. The ground floor is divided into several rooms. The first room, the largest at full height, houses the fireplace for processing milk and the beams on which the cheese wheels were placed for aging. The other rooms are obtained from a subdivision of the main space with wooden walls, an expression of a construction technique widespread in the valley but ordinarily demolished.

The roof, unique for the whole body of the building, has recently been remodelled and has some corrugated walls now deformed by weight. As per tradition, stones had been placed on the roof in order to stop the tiles (from falling).

The site is subject to a landscape restriction, so in the elaboration of the project a discussion was carried out with the Superintendence of Brescia, with whom it was agreed to extend the structures on the site of the volumes inferable from the historical cadastre, to meet the needs of future use.

The proposed uses, after the debate of the future managers, include a residential area located in the largest building (Building A), with the introduction of rooms for receptive use inside the bunkers: single or double rooms, which can be connected vertically. Accessibility for disabled guests has been guaranteed in all the rooms on the ground floor.

On the first floor, rooms are accessible by descending a few steps going under the external level, as it happened in the past when hay used to be brought inside the building. The current stable will house the bar and breakfast area of future the Bed \& Breakfast ${ }^{4}$. In the annexed part will live the manager of the structure, who will have access to an apartment and to the laboratory for processing products.

Building B is intended for training and aggregation activities at different levels: schools of all levels, cultural groups, local associations, etc. In the room where the fireplace is located are grouped the management services of the centre and the toilets, while in the second space will take place training or meetings.

process that was developed at the same time as the architectural design phase and continues during the works, with fortnightly meetings between the work management, the Mountain Community of Valle Trompia and the managers. 
The project attempts to represent a virtuous model in which are carried out good recovery practices aimed at demonstrating how respect for traditional building methods does not clash with modern life habits, but positively interlaces them with knowledge.

In the construction phase, now under contract, has been possible to experiment innovative solutions (to be exported as operational methods) regarding systems of structural consolidation and earthquake-proofing common in architecture with a monumental character but not evaluated by local technicians. The reasons are two: first, the operators don't know the solutions proposed for rural architecture. Second, they are afraid that costs will be significantly higher than the ordinary solutions normally used for new constructions (the project forecasts a box roof with steel kerb (Figure 10); new floors, independent from the historical masonry and supported by steel pillars; the insertion of artificial connections in the rooms that housed the old beams; the lintels of the doors and windows flanked by steel lintels).

Heating is guaranteed by a wood fire boiler located in the basement of Building B, which covers the whole complex. The choice of wood as fuel originated from the discussion between the future managers, who evaluated the abundance of wood harvested by cleaning the woods and undergrowth of the valley. In order to comply with the regulations, energy insulation solutions inspired by tradition but reinvented in a modern key have been provided, such as internal coats in natural fibres (bamboo reeds, hemp lime bricks, wood fibre) obtained from the agricultural chain (Figure 11).

The doors and windows, when present, have been preserved or integrated (if there was no glass) and supported by a second internal window and door, laid inside the opening.

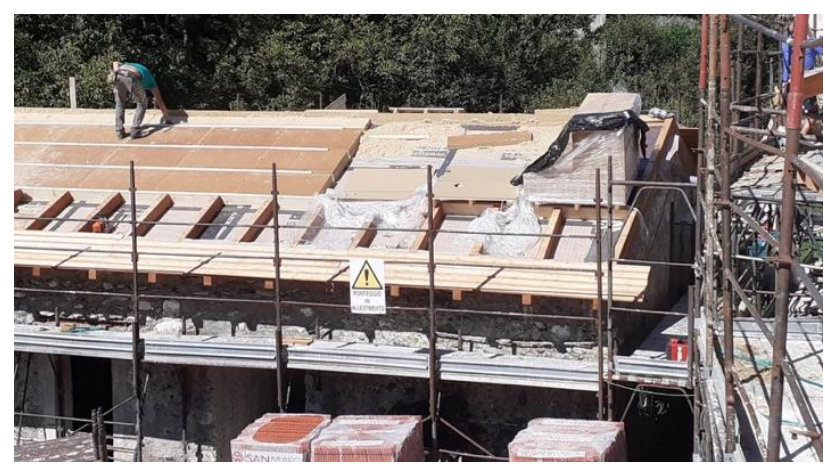

Figure 10. Example of an intervention data sheet.

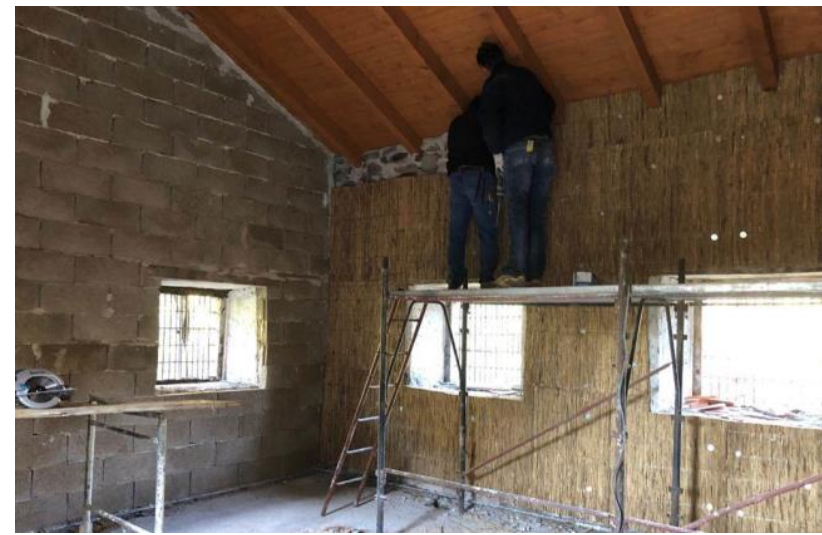

Figure 11. Isolation with bamboo reeds.
As far as the electricity supply is concerned, we have remained tied to the suppliers of the area. In the meantime, some proposals have been subjected to the Province offices for the installation of hydroelectric power plants, which are widely used in the area. A priori, the installation of photovoltaic panels has been excluded not only from an aesthetic point of view but also due to the verified inefficiency of the plant in this area, where the sun shines only for a few hours during the summer days and almost never during the winter season. The finishes of the annexed portion have been studied to make it harmoniously integrated with the building complex: the masonry is not made of stone but there is a covering in 'peels', wood claddings laid in the same way as those found in the farmsteads (Figure 12).

From a conservative point of view, the choices made have respected a traditional use of the materials also in the technological solutions introduced, which provides a physical and practical demonstration of the possibility to operate in a respectful way in rural architecture (Figure 13).

In order to follow the paths already started in other calls for proposals by the Cariplo Foundation, at the end of the works the building will be provided with a planned conservation project of the building, guaranteeing a monitoring phase over its correct use. In this phase an HBIM model of Building B is being run-in in order to continue the experiments already carried out in other sectors.

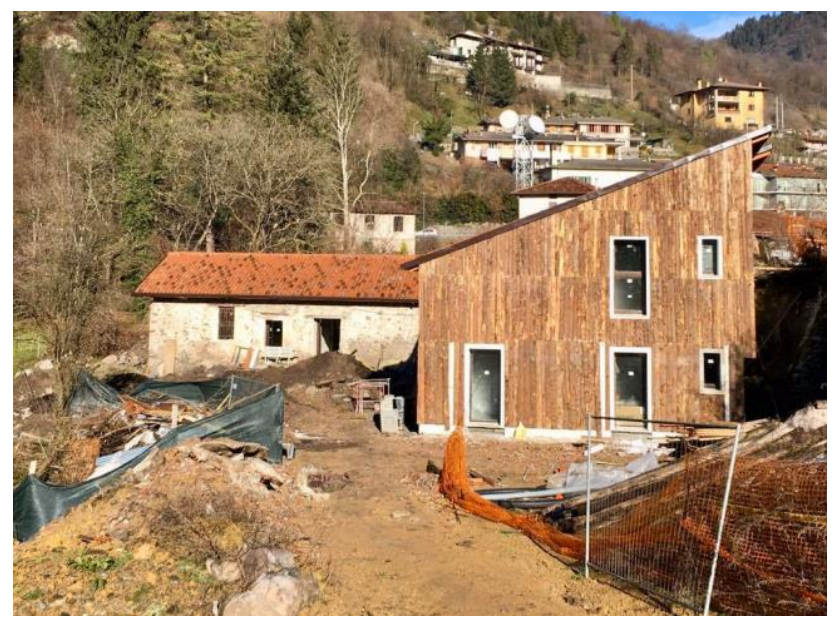

Figure 12. The masonry is covered in wood 'peels'.

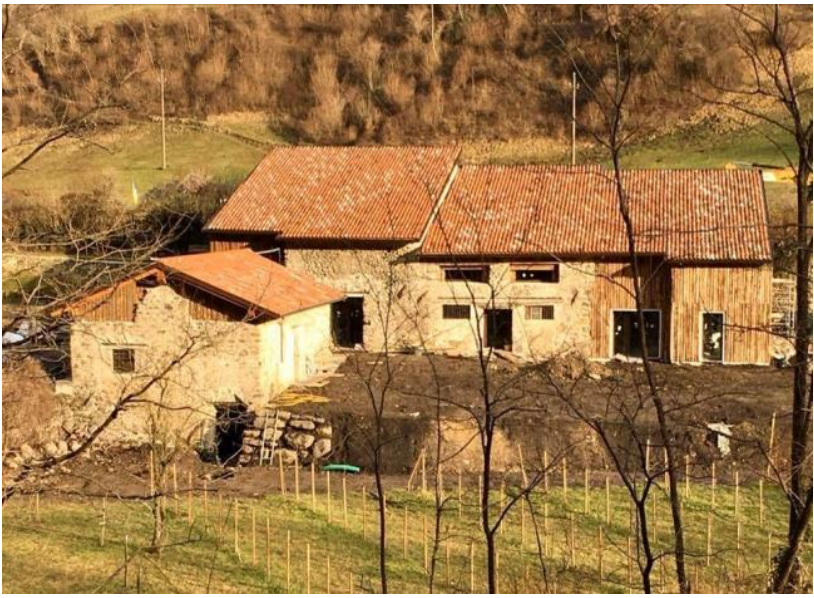

Figure 13. The masonry is covered in wood 'peels'. 


\section{CONCLUSION}

Depopulation and reduction of services and opportunities characterize many areas. To fight this tendency, it is important to adopt a change in perspective, to overcome the individual isolation and embrace a collective dimension, in order to share difficulties but most of all, solutions.

The programme "Attiv-Aree", herewith presented through one of its driver, has come to conclusion and, despite the fact that the skills needed to respond positively and interpret correctly the call were not to be taken for granted, the outcome can be considered positive.

The programme actually concerned the introduction of original and heterogeneous planning abilities that acted as a lever on the unexpressed resources of the communities in which we took action.

A key role in these three years of work was played by the networks, which involved authorities and people willing to modify their own way of acting and way of living their everyday life. We refer to networks when we speak about small businesses, touristic hospitality businesses, services in support of the weaker citizens. The results arrived, both in terms of touristic response and of a greater economic sustainability.

In these territories, the change understood in cultural terms brought by the recovery of the local identity and by a shift in perception that caused the passage from an isolation dimension to a collective one, has taken place through a process of research on the historical architectures.

In fact, it is not possible to live and love a place without knowing it, and the mapping of the artifacts that strongly identify the areas (just think, for example, of the rural buildings or the elements of industrial archaeology) has now taken on a strategic role. The engagement of citizens and young people in the discovery and rediscovery of the historical architecture has contributed to a triple result: the identification of the resource, the takeover of it as a local heritage, the awareness of the population role in the management of the resource. Working directly on the historical structure has helped people understand how culture plays a strategic part both in the growth of our identity and in the respect of our own heritage, developing a critical and rational thinking.

The meetings and training activities have also been crucial factors in establishing a dialogue between the recovery intervention planning, the maintenance of the architectural works and the sector regulations, always seen as obstructive in every new venture. In this scenario, the active role played by institutions, professionals and, in general, by citizens as protectors of their own territory was supported by the ability of sharing purposes in order to bring back the material integrity and functional efficiency of the historical centres, so that they could be testimony of cultural and material values.

Finally, the example of Rebecco represents an operative testimony that the path undertaken can have a continuity. In Rebecco, the ancient crops will grow next to the experimental cultivations and tourists will find a dynamic environment due to a hospitality structure managed according to a model of sustainable and experiential tourism, a multifunctional centre for educational workshops, guided visits, cultural and enogastronomic events, which will form the basis of the calendar of events related to training, education and the promotion of the territory.

\section{REFERENCES}

Agostini S. 2007, Architettura rurale: la via del recupero. Alternative d'intervento sull'esistente, Milano, Libreria Clup.

Aliverti L., Della Torre S., Gnone M., Leoni M., Musso S. 2006, Guida alla manutenzione e al recupero dell'architettura rurale intelvese, Lipomo, Cesarenani tipografia editrice.

Bellini A. 1996, A proposito di alcuni equivoci sulla conservazione, TeMa, n. 1, p. 2-3.

Della Torre S., 2015, Shaping Tools for Built Heritage Conservation: from Architectural Design to Program and Management. Learning from "Distretti culturali"., in Van Balen K., Vandesande A. (eds.), Community involvement in heritage, Antwerp - Apeldoorn, Garant, p. 93-101.

Dezzi Bardeschi M., 1991, Restauro: punto e da capo. Frammenti per una (impossibile) teoria, Milano, Angeli.

De Vita M., 2009, Città storica - edilizia sostenibile, un programma di sperimentazione avanzata, in De Vita M. (ed.), Città storica e sostenibilità, Atti del Convegno, Firenze 17 marzo 2009, Firenze, Edizioni Regione Toscana, p. 31-65.

Francini M., Palermo A., Viapiana M.F., 2017, Aree interne: un'importante 'inclinazione' territoriale per integrate politiche di coesione, Territorio, n.8.Franco Angeli, Milano.

Lemair R. M.,1997, Patrimonine et identité culturelle, in Vanden Bemebn Y. (ed.), Premières rencontres du Amèrique latine-Europe. Monuments, sites et documents historiques, Facultés Universitaire Notre-Dame del la Paix, Namur, 10-13 settembre 1996, Namur, Presse Universitaires de Namur, p. 299-301.

Marchesi G., 2003, Quei laboriosi valligiani. Economia e società nella montagna bresciana tra il tardo Settecento e gli anni postunitari Brescia, Grafo.

Moioli R., Baldioli A., 2018, Teoria, norme e iniziative esemplari, Conoscere per conservare. 10 anni per la Conservazione Programmata, Quaderni dell'Osservatorio, n. 29, p. 7-18.

Musso S. F., Franco G., Gnone M. 2008, Architettura rurale nel parco del Beigua. Guida alla manutenzione e al recupero, Venezia, Marsilio.

Pracchi V. (ed.) 2008, Pratiche costruttive storiche. Manufatti in stucco e strutture lignee di copertura in edifici lombardi, Como, NodoLibri.

Simoni C., 2010, La via del ferro e delle miniere in Valtrompia, Grafo, Brescia.

Scala B., Boniotti C., 2020, Il patrimonio architettonico montano rurale della Valle Trompia Linee guida alla conoscenza e alla conservazione, Nardini, Firenze.

Treccani G. P., 1996, Pratiche costruttive e progetto di conservazione, in Della Torre S. (ed.), Storia delle tecniche murarie e tutela del costruito. Esperienze e questioni di metodo, Milano, Guerini, p. 277-287.

Veronesi F., 2015, Nella Valle Trompia, in Paoletti D., Fappani A. Paesaggi Agrari ed Architetture Rurali nel Territorio Bresciano, vol II, Fondazione Civiltà Bresciana, Brescia. 